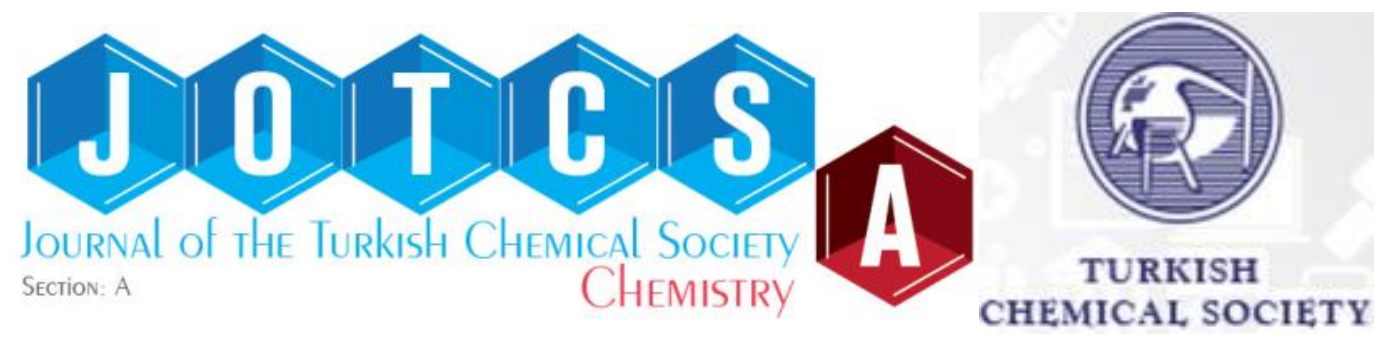

\title{
Enhancement of Cerium exchange with Ultrasound
}

\author{
Fehime Çakıcıoğlu-Özkan*1, Yasemin Erten-Kaya², \\ ${ }^{1}$ Izmir Institute of Technology, Department of Chemical Engineering, \\ Urla, İzmir, Turkey \\ ${ }^{2}$ General Directorate of İzmir Water and Sewerage Department, Material Available and \\ Package Treatment Branch Manager, 35251, İzmir, Turkey
}

(This article first appeared in PPM2017 and was accepted as a non-peer-reviewed manuscript to be published in JOTCSA)

\begin{abstract}
In this study the effect of ultrasound of the cerium exchange was studied. The results were compared to those obtained from traditional batch exchange method. Contact time, initial cation concentration (fold equivalent excess) and the types of the ultrasound were studied. Ultrasonic probe, which is the most effective method, enhanced the replacement of $\mathrm{Na}^{+}$ion with $\mathrm{Ce}^{3+}$ ion in the extra-framework of zeolite up to $73 \%$ by applying 5 consecutive ion exchanges. The cerium in the solution caused to be formed cerium oxides on the crystal surface occluding the pores. Thus the specific surface area of cerium exchanged zeolite was decreased due to formation of cerium complexes on the surface and into the pores.
\end{abstract}

Keywords: NaX zeolite; Ultrasound; Ion exchange; Characterization.

Cite this: Çakıcıoğlu-Özkan F, Erten-Kaya Y. Enhancement of Cerium exchange with Ultrasound. JOTCSA. 2018;5(sp. is. 1):53-64.

*Corresponding author: E-mail address: yaseminerteniyte@gmail.com Tel.:

+902322936704; Fax: +902322936705 


\section{INTRODUCTION}

Ion exchange generally is performed by using traditional batch exchange method. However, ultrasound can be an alternative method to apply ion exchange in zeolites. In this work, zeolite $\mathrm{NaX}$ was used to perform ion exchange by using both methods. Zeolites are microporous, crystalline aluminosilicate minerals with a cage like structure of $\mathrm{AlO}_{4}$ and $\mathrm{SiO}_{4}$ tetrahedra bound by shared oxygen atoms. The crystal structure consists of sodalite cages through double six-rings (D6R) and supercage accessible by a three-dimensional 12-ring pore system (Figure 1). As a consequence, different sites are observed. The principle sites of zeolite $X$ are; site I in the center of the hexagonal prism, site II and site III in the single six-membered ring (S6R) and near the four-ring windows of the supercage [1]. Zeolite $X$ can accommodate variety of cations, such as $\mathrm{Na}^{+}, \mathrm{K}^{+}$, $\mathrm{Ca}^{2+}, \mathrm{Mg}^{2+}$ and others at these sites in the unit cell of $\mathrm{X}$ zeolite structure. These cations are mobile and can readily be exchanged for others in a contact solution $[2,3]$. The trivalent cation, $\mathrm{Ce}^{3+}$ ion, prefer to locate site $\mathrm{I}$, the most stable site rather than site II as stated by Jasra et al. [4]. Location of $\mathrm{Ce}^{3+}$ ions determine the application field of zeolite in industry.

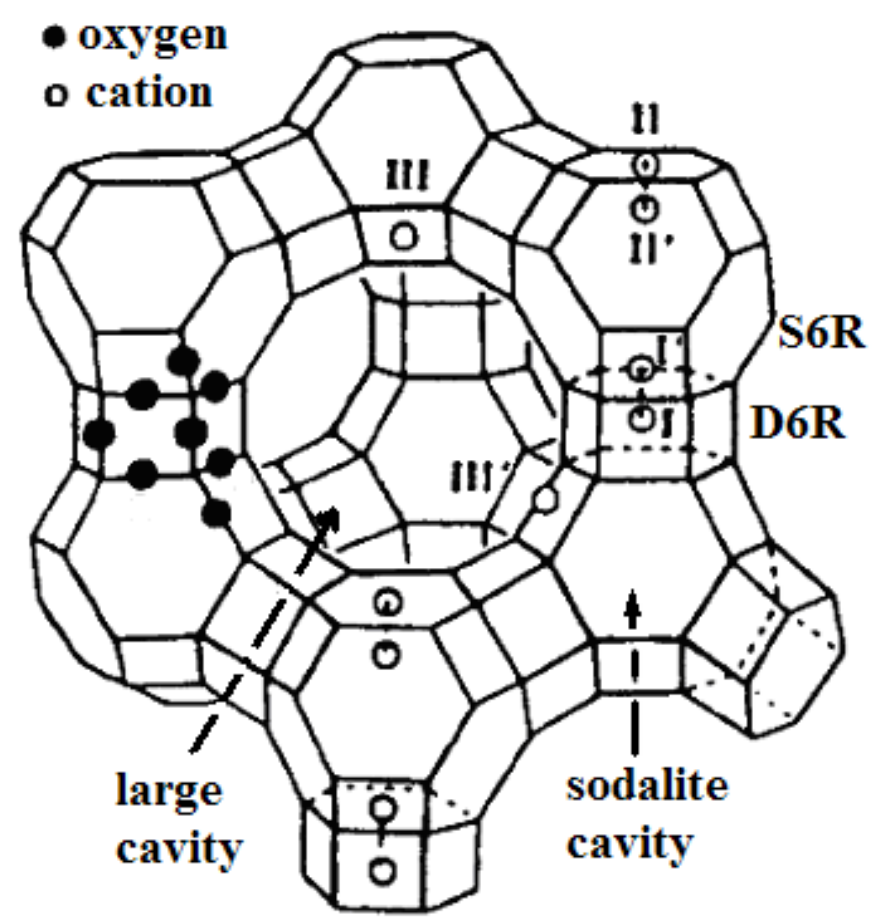

Figure 1: Unit cell structure of NaX zeolite with cation sites [1].

Ultrasound is a source of high energy vibrations that produces ultrasonic waves with frequencies. There are three main types of ultrasonic (US) sources; gas driven, liquid driven and electromechanical. Electromechanical sources are based on the piezoelectric and magnetostrictive effects used when homogenization and efficient mixing are required. Piezoelectric transducer is the most commonly used in power bath and probe- 
Çakıcıoğlu-Özkan F, Erten-Kaya Y. JOTCSA. 2018; 5(sp. is. 1); 53-64.

type sonicators which are used generally by analytical chemists and operated at a fixed frequency; $20 \mathrm{kHz}$ for common probe systems and $40 \mathrm{kHz}$ for baths. Ultrasonic probes are generally preferred in order to use in analytical chemistry comparing to the ultrasonic baths [5]. The origin of the ultrasonic effect is the collapse of millions of micro bubbles created by ultrasonic irradiation. By this way, the mechanism of ultrasound can contribute to mass transfer enhancement [3].

The goal of this work is to investigate the effect of the ultrasound type on $\mathrm{Ce}^{3+}$ ion replacement kinetics in Zeolite NaX. This study is designed to understand the effect of ultrasonic source on the mass transfer.

\section{EXPERIMENTAL}

Zeolite $\mathrm{NaX}(13 \mathrm{X})$ in the crystal size of $2 \mu \mathrm{m}$ was used in binderless form (Aldrich). Cerium $\left(\mathrm{CeCl}_{3} .7 \mathrm{H}_{2} \mathrm{O}\right)$ salts with high purity of $99.6 \%$ was used in the ion exchange experiment. The ion exchange experiments were carried out by contacting NaX zeolite with $\mathrm{CeCl}_{3} .7 \mathrm{H}_{2} \mathrm{O}$ solution $(0.08 \mathrm{M})$ including $3,5,6$ and 9 fold excess $\mathrm{Ce}^{3+}$ ions, theoretically needed amount to completely exchange the $\mathrm{Na}^{+}$ions, in solution $(\mathrm{pH}=5.5$ \pm 0.25 ) at $70{ }^{\circ} \mathrm{C}$. The exchange solutions were centrifuged (Rotofix 32, Hettich) and washed several times to obtain $\mathrm{Cl}^{-}$free Zeolite.

The ultrasound processor (Sonics-Vibra Cell 505) with $20 \pm 0.050 \mathrm{kHz}$ frequency and 25 and $40 \%$ of acoustic power $(500 \mathrm{~W}$ ) were used in the experiments. The processor has the replaceable probe tip having $1 / 2^{\prime \prime}(13 \mathrm{~mm})$ diameter. The probe was dipped to a depth of $15 \mathrm{~mm}$ and the temperature of the solution sonicated was maintained at $70{ }^{\circ} \mathrm{C}$ with circulating water (Figure 2). Ultrasonic bath at $35 \mathrm{kHz}$ and $320 \mathrm{~W}$ was also used in order to perform the ion exchange at different frequency and power. The experimental conditions in the ion exchange by using ultrasound; ultrasonic probe and ultrasonic bath are tabulated in Table 1. Traditional batch ion exchange experiments were performed in the water bath shaker (GFL 1092) at $70{ }^{\circ} \mathrm{C}$ and $130 \mathrm{rpm}$. All experiments were provided for a sufficient time to enable the system to approach equilibrium. The experiments were repeated at least two times. Inductively Coupled Plasma Atomic Emission Spectroscopy (ICP-AES 96, Varian) was used to determine the cation content of the aqueous solution centrifuged. 


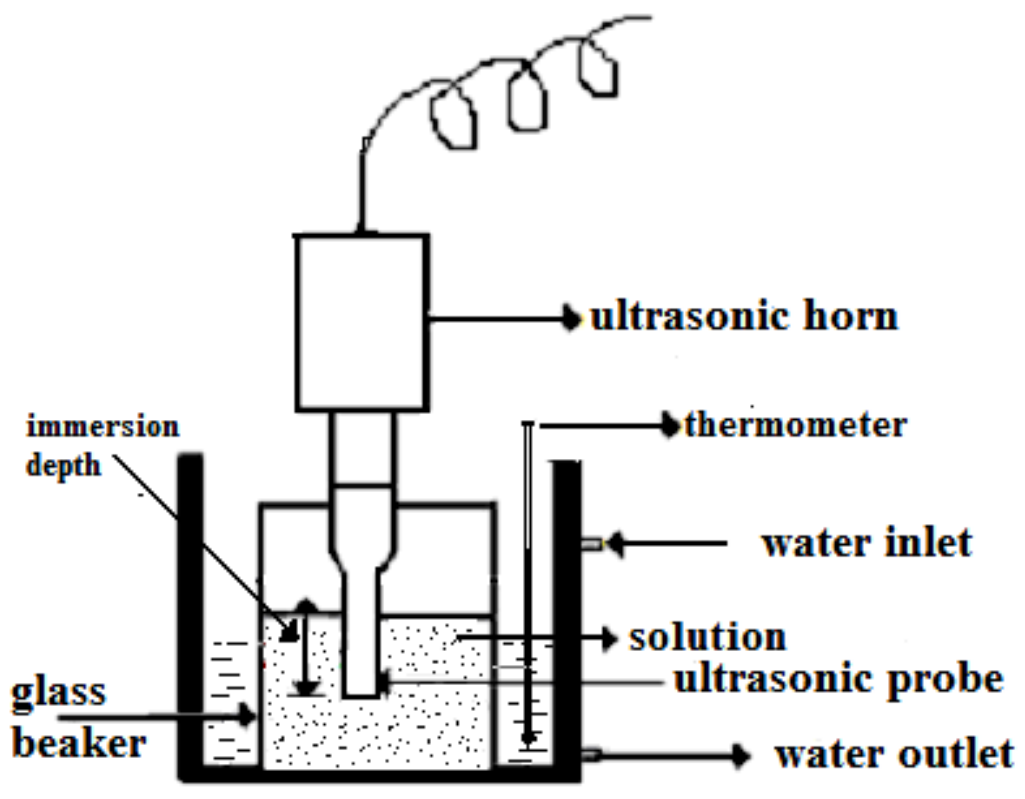

Figure 2: Experimental set-up of ultrasonic probe.

Table 1: Experimental conditions of the types of ultrasound used in the ion exchanges.

\begin{tabular}{lccc}
\hline Codes $^{*}$ & Types of Ultrasound & Power & $\begin{array}{c}\text { Frequency } \\
\text { (kHz) }\end{array}$ \\
\hline U-125W & Probe & 125 & 20 \\
U-200W & Probe & 200 & 20 \\
UB-320W & Bath & 320 & 35
\end{tabular}

${ }^{*} \mathrm{U}$ : ultrasonic probe; UB: ultrasonic bath

Consecutive ion exchange experiments in which the solution was refreshed five times for each 30 min was applied to obtain fully exchanged zeolite. $\mathrm{Ce}^{3+}$ ion solutions with 5 fold equivalent excess were used in all consecutive ion exchange experiments.

In the codes the numbers $(3,5,6$ or 9 ) and the following letters ( $T$ :traditional, $U$ : ultrasonic probe and UB: ultrasonic bath) were used for the fold excess and the methods, respectively. In the characterization of the Ce-rich zeolites obtained with the five consecutive ion exchange experiments; X-ray diffraction (XRD), scanning electron microscopy (SEM) and volumetric adsorption were used. Crystallinity of the zeolites were determined by X-ray diffraction (Philips X-Pert Pro Diffractometer) using CuKa radiation at $45 \mathrm{kV}$ and $40 \mathrm{~mA}$ in the $2 \theta: 5^{\circ}-70^{\circ}$ with $0.2^{\circ}$ step size. The micrographs of the zeolite crystals were taken by using scanning electron microscopy (SEM, Philips $\mathrm{XL}$ 30S) with LFD and ETD detector at 5.00 and $3.00 \mathrm{kV}$ under vacuum conditions. Textural properties of zeolites such as surface area were determined by using volumetric 
adsorption instrument (Micromeritics, ASAP 2010). Prior to adsorption, the samples were degassed for $24 \mathrm{~h}$ under vacuum better than $10^{-5}$ mbar at $350{ }^{\circ} \mathrm{C}$.

\section{RESULTS AND DISCUSSION}

\section{Kinetic studies}

The effect of fold equivalent excess of the $\mathrm{Ce}^{3+}$ ion solution to be introduced in the presence of ultrasonic probe $(125 \mathrm{~W})$, in the ion exchange were examined kinetically. The results were compared with those obtained from traditional batch method.

The ion exchange performed in this study ;

$$
M_{(a q)}^{z+}+N a-X_{(z e o)} \longrightarrow z N a_{(a q)}^{+}+M-X_{(z e o)}
$$

where $\mathrm{M}^{\mathrm{z}+}$ is the counter ion, namely $\mathrm{Ce}^{3+}$. Assuming that $\mathrm{Ce}^{3+}$ ions were exchanged with only $\mathrm{Na}^{+}$ions into zeolite, the exchange percent of $\mathrm{Na}^{+}$ion $\left(\eta_{\mathrm{Na}}\right)$ was calculated;

$$
\eta_{N a}=\left(\frac{q_{o}-q_{N a}}{q_{o}}\right) x 100
$$

where $\mathrm{q}_{\mathrm{o}}$ and $\mathrm{q}_{\mathrm{Na}}\left(\mathrm{mg} \mathrm{g}^{-1}\right)$ are the amount of $\mathrm{Na}^{+}$ions into $\mathrm{X}$ zeolite initially and at any time $t$, respectively.

As seen from the kinetic curves of $\mathrm{Ce}^{3+}$ ion exchange (Figure 3), ion exchange was very fast initially and thereafter it slowed down. Ultrasound enhanced the exchange percent by means of transient cavitation bubbles with the theory of "hot spots" [5]: Hot spots increase the temperature and pressure near the surface of the Zeolite NaX causing enhancement in the cation exchange [6] compared to the traditional method $[7,8]$. As seen from Figure 3, the excess amount of $\mathrm{Ce}^{3+}$ ion in the solution causes to increase the equilibrium exchange percent up to $\% 65$ for 5 fold excess when ultrasonic probe was used, whereas the exchange percent is increased gradually in case of the traditional method. The difference between the methods disappeared at 9 fold excess. As stated in the literature [9], cerium has a tendency to hydrolyze with increasing concentration which prevents $\mathrm{Ce}^{3+}$ ions to enter the zeolite framework. As a result, ultrasonic method may have accelerated the hydrolysis of $\mathrm{Ce}^{3+}$ ions after the 5 -fold excess compared to the traditional method. 

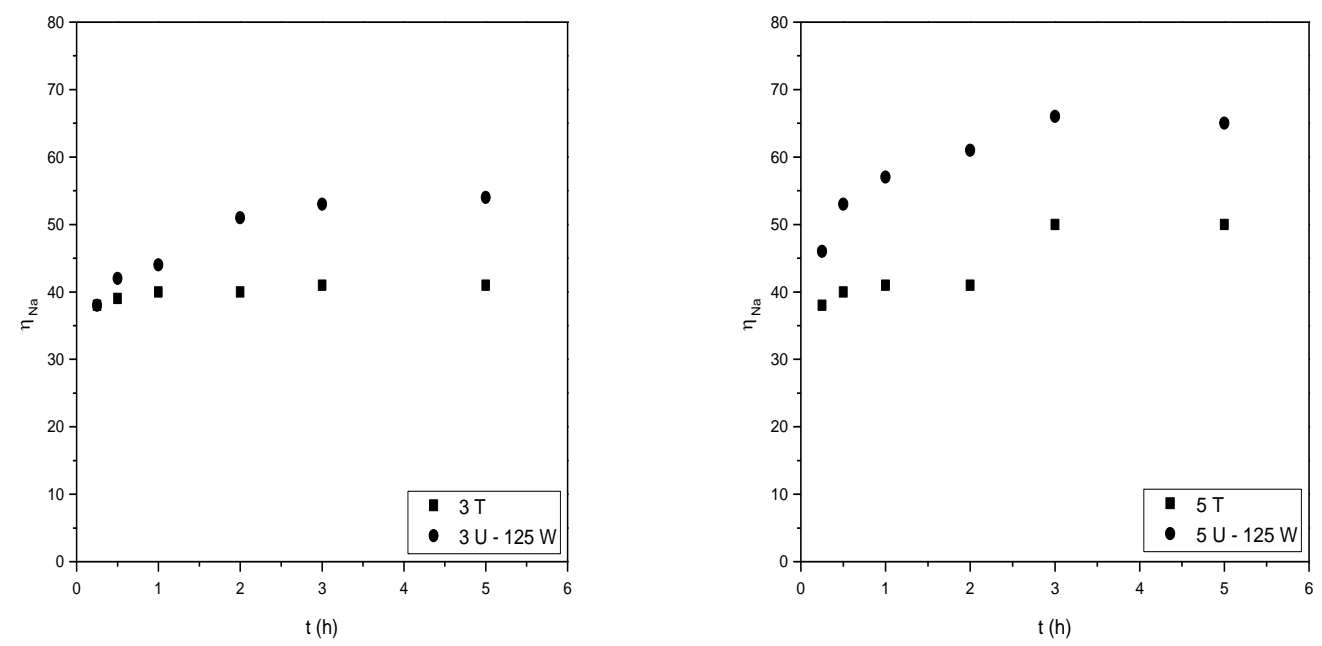

(a) (b)

Figure 3: Kinetic curves of $\mathrm{Ce}^{3+}$ ion exchange (fold excess: (a) 3 (b) 5 c) 6 (d) 9).

\section{Effect of ultrasonic types}

Two types of ultrasound method (ultrasonic probe and ultrasonic bath) were used in ion exchange experiments to investigate the effect of their frequency and power on ion exchange experiments. As seen from the kinetic curves of $\mathrm{Ce}^{3+}$ ion exchange (Figure 4), ultrasonic probe method is more effective than ultrasonic bath method. Although ultrasonic probes deliver their energy on a localized zone, it provides a great many transient cavitation bubbles not only in the fluid phase surrounding the particles but also in the solution within the porous particles. Therefore it was observed that ultrasonic probe method enhanced the exchange compared with the traditional method and ultrasonic bath method. The exchange percent was changed depending on the method and the type of the ultrasound used: U-125W > U-200W > T $\geq$ UB-320W.

The higher exchange amount was obtained as the lower power was applied. It can be explained with the frequency and power used. Because acoustic power through the liquid causes large number of cavitation bubbles many of which coalesce into larger, longer lived bubbles that will give rise to hinder the acoustic energy through the liquid as stated by Castro and Capote (2007). If the frequency used in ion exchange increased, cavitation bubbles became initially difficult since the frequency affects the threshold intensity and performance of the ultrasound in ion exchange. Therefore, suitable power and frequency should be selected according to the process. 

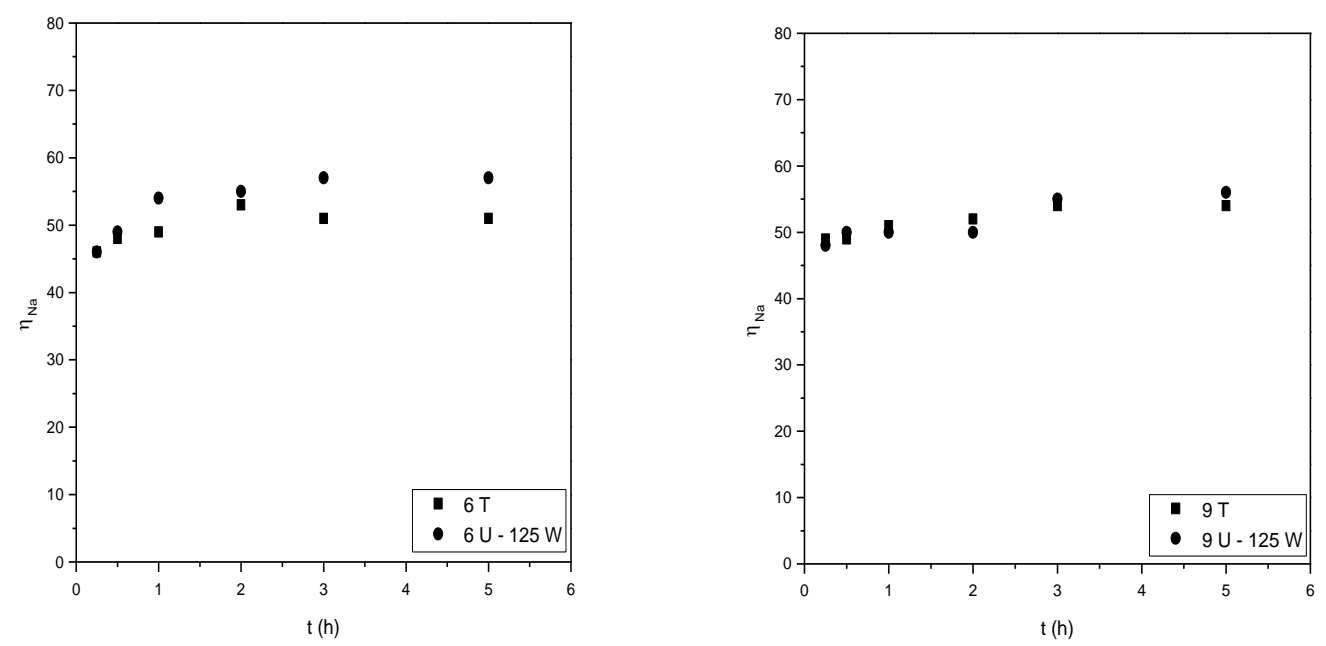

(c) (d)

Figure 4: Comparison of kinetic curves obtained for 5 fold excess cerium.

\section{Enhancement of Exchange with consecutive ion exchange}

Equilibrium experiments were conducted by refreshing the counter ion $\left(\mathrm{Ce}^{3+}\right)$ in the solution. As seen from Figure 5, ultrasonic probe (125 W) was used in consecutive ion exchanges and compared with traditional batch method in 5 fold excess cerium solutions. Figure shows the change in the exchange percent of $\mathrm{Na}^{+}$ion with number of consecutive ion exchange. The highest exchange of $\mathrm{Na}^{+}$ions was observed with the $1^{\text {st }}$ consecutive ion exchange experiment. On the other hand almost no exchange in the $5^{\text {th }}$ consecutive ion exchange was obtained. However the effect of the method is evident in $\mathrm{Ce}^{3+}$ ion exchange; $62 \%$ from traditional method and $73 \%$ from ultrasonic method. As a conclusion, the cerium is partially exchanged due to other effects such as agglomeration of cerium oxide on the crystal surface with the consecutive exchanges. Hence fully cerium exchanged zeolite $X$ cannot be obtained. 


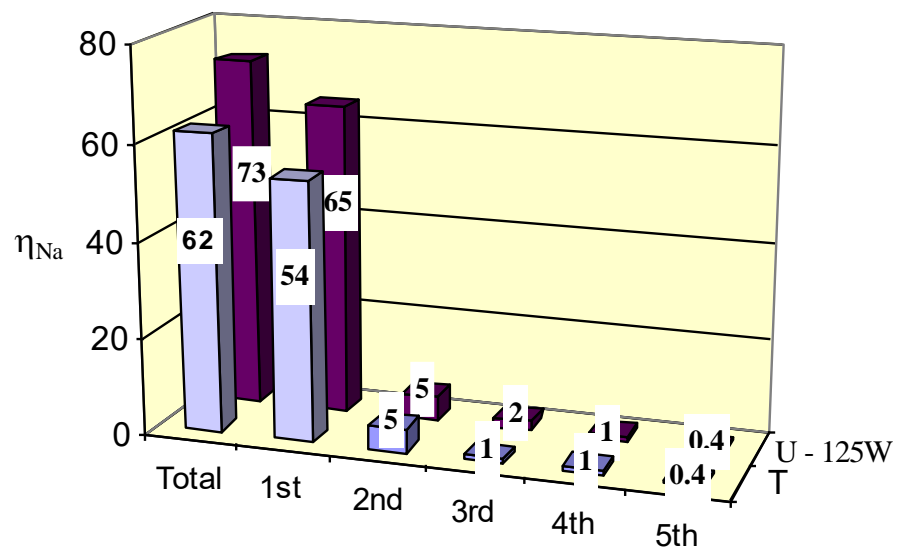

Consecutive ion exchange

Figure 5: The effect of consecutive ion exchange on the exchange Na amount (\%) for; traditional $(T)$ and ultrasonic probe $(\mathrm{U}-125 \mathrm{~W})$ methods.

\section{Characterization Studies}

The characterization studies were applied to Ce-exchanged zeolite obtained after 5 consecutive ion exchange experiments. The structural and textural properties of the zeolites were investigated by using volumetric adsorption system, X-Ray diffractometer (XRD) and scanning electron microscope (SEM).

$\mathrm{N}_{2}$ adsorption isotherms of the zeolites are shown in Figure 6. According to the IUPAC classification, $\mathrm{N}_{2}$ adsorption isotherms of the $\mathrm{NaX}$ zeolite and Ce-rich zeolite obtained from traditional and ultrasonic probe methods are of Type I. The U-125 W zeolite with microporous structure has the lowest adsorption amount at $77 \mathrm{~K}$ and $1 \mathrm{~atm}$. The isotherm data obtained were evaluated for the textural properties of the zeolites and tabulated (Table 2). The specific surface area and micropore volume was decreased when the $\mathrm{Na}^{+}$ions are exchanged with $\mathrm{Ce}^{3+}$ ions. Because cerium oxides block the accessible pores, complexes have formed. 


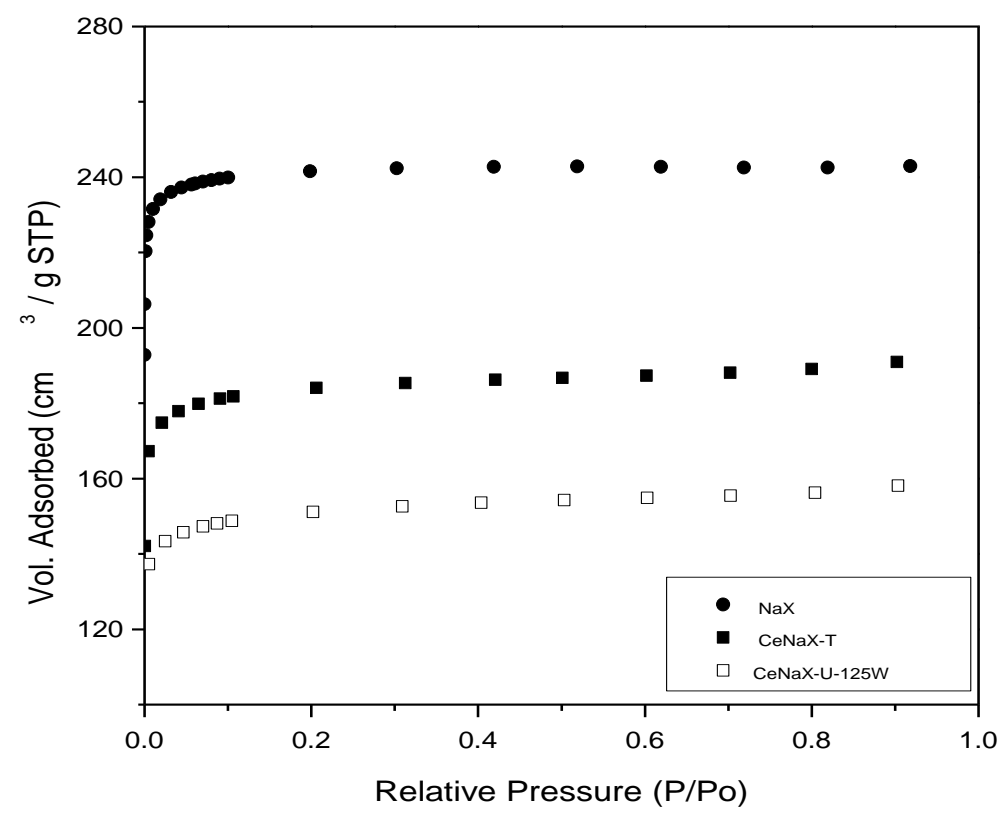

Figure 6: $\mathrm{N}_{2}$ adsorption isotherms of $\mathrm{NaX}$, and cerium exchanged zeolite with traditional (CeNaX-T) and ultrasonic probe (CeNaX-U-125W) methods.

Table 2: Textural properties of the zeolites obtained with consecutive ion exchanges.

\begin{tabular}{lcccc}
\hline Zeolite Codes & $\begin{array}{c}\text { Exchange } \\
\text { amount } \mathbf{( \% )}\end{array}$ & $\begin{array}{c}\text { Area } \\
\left(\mathbf{m}^{\mathbf{2}} \mathbf{g}^{-\mathbf{1}}\right)\end{array}$ & $\begin{array}{c}\mathbf{V}_{\text {mic }} \\
\left(\mathbf{c m}^{\mathbf{3}} \mathbf{g}^{-}\right.\end{array}$ & $\begin{array}{c}\text { DMedian } \\
\mathbf{1})\end{array}$ \\
\hline $\mathrm{NaX}$ & --- & 1058 & 0.37 & 5.67 \\
$\mathrm{~T}$ & 62 & 809 & 0.28 & 7.29 \\
$\mathrm{U}-125 \mathrm{~W}$ & 73 & 666 & 0.23 & 8.28
\end{tabular}

$A^{L}$ : Surface area from Langmuir method; DMedian and Vmic: Median diameter and micropore pore volume calculated from Horvath-Kawazoe Method

Figure 7 shows the X-ray diffractogram of the zeolites. The cation exchange resulted in the missing of some peaks due to the cerium oxide occluded on the crystal surface as mentioned in the literature $[11,12]$. This means that X-ray diffraction studies of the zeolites in powders confirm the migration of cerium to the extra-framework sites of Zeolite $\mathrm{X}$. 


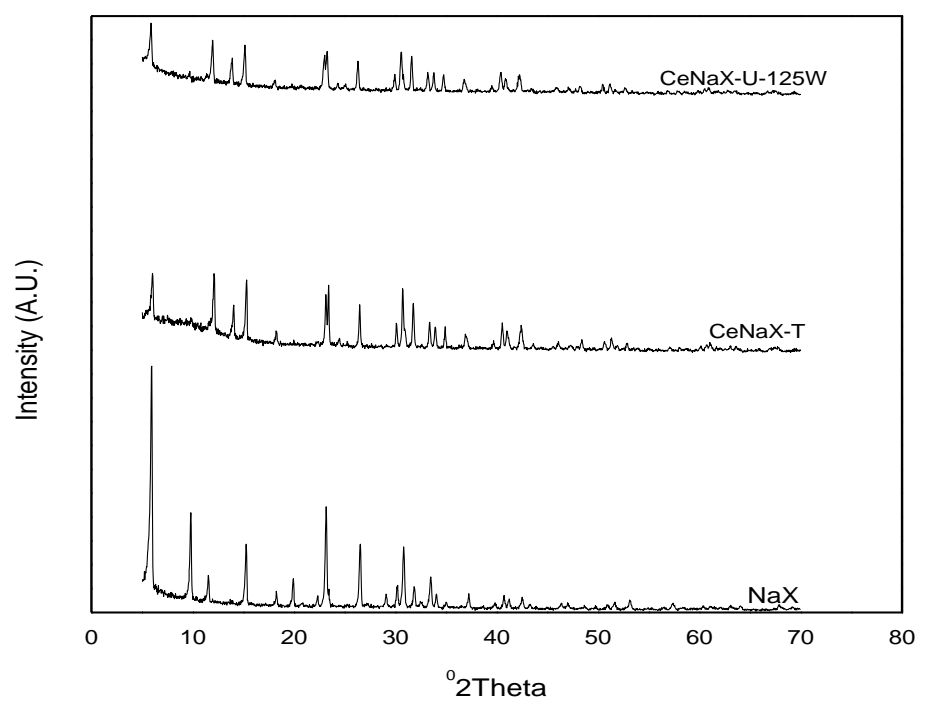

Figure 7: X-ray diffraction patterns of $\mathrm{NaX}$ and cerium exchanged zeolite with traditional (CeNaX-T) and ultrasonic probe (CeNaX-U-125W) method.

SEM images of the zeolite surfaces shows the changes in the crystals of cerium rich zeolite $\mathrm{X}$ conforming the occlusion of cerium oxide on the crystal..

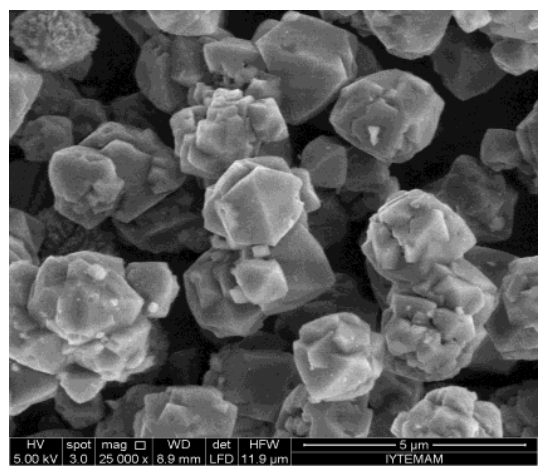

(a)
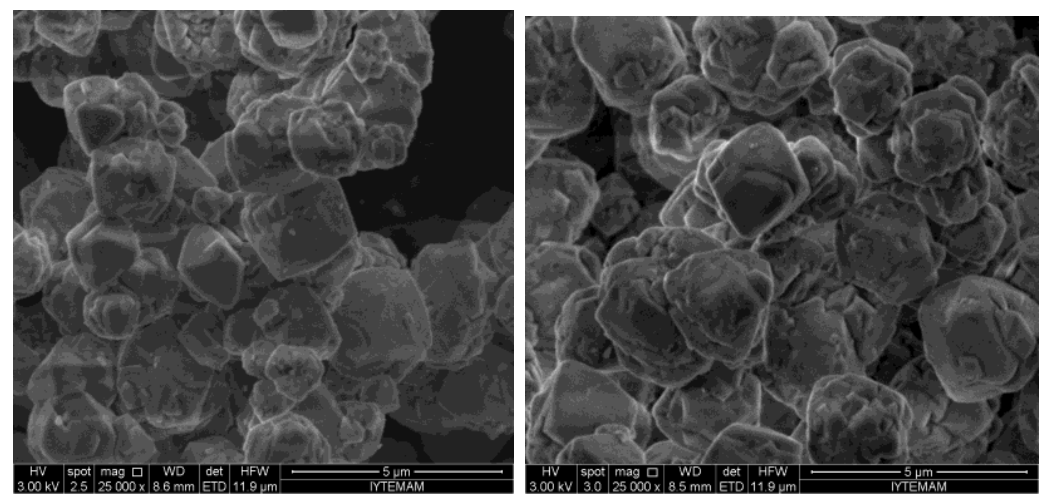

(b) (c)

Figure 8: SEM images of zeolites: (a) $\mathrm{NaX}$ (b) T (c) U-125W. 


\section{CONCLUSION}

The effect of the ultrasonic irradiation on the $\mathrm{Ce}^{3+}$ ion exchange was investigated. The present study shows that the use of ultrasonic probe with $125 \mathrm{~W}$ during ion exchange significantly affects the exchange amount at equilibrium which acted like a co-driven force of concentration of $\mathrm{Ce}^{3+}$ ions in solution due to cavitation effect of ultrasonic field and increased the exchange amount in ion exchange process. This situation did not accelerate the exchange of $\mathrm{Na}^{+}$with $\mathrm{Ce}^{3+}$ ions, as observed in $\mathrm{Na}^{+}$exchange with $\mathrm{Li}^{+}$ ions in our previous paper, but enhance the amount of exchange. The cerium in the solution caused to be formed cerium oxides on the crystal surface occluding the pores and partially exchange was obtained. Thus the specific surface area of cerium exchanged zeolite was decreased due to formation of cerium complexes on the surface and into the pores.

\section{ACKNOWLEDGEMENT}

The authors would like to thank Izmir Institute of Technology (Project number: 2006IYTE31) and State Planning Organization of Turkey (DPT) for financial support.

\section{REFERENCES}

[1] N.D. Hutson, S.U. Rege, R.T. Yang, Mixed cation zeolites: $\mathrm{Li}_{x} \mathrm{Ag}_{y}-\mathrm{X}$ as a superior adsorbent for air separation, Separations 45 (1999) 724-734.

[2] V.H. Bekkum, E.M. Flanigen, P.A. Jacobs, J.C. Jansen, Introduction Zeolite Science and Practice, second completely revised and expanded edition, Elsevier Science, 2001.

[3] Y. Erten-Kaya, F. Cakicioglu-Ozkan, Effect of ultrasound on the kinetics of cation exchange in NaX zeolite, Ultrasonics Sonochemistry, 19 (2012) 701-706.

[4] R.V. Jasra, N.V. Choundary, S.G.T. Bhat, Correlation of sorption behaviour of Nitrogen, Oxygen, and Argon with cation locations in zeolite X, Ind.Eng.Chem. Res. 35 (1996) 4221-4229.

[5] M.D. Castro, F.P. Capote, Techniques and Instrumentation in Analytical Chemistry: Analytical Applications of Ultrasound, Volume 26, Elsevier B.V., 2007.

[6] M.H. Entezari, M. Tahmasbi, Water softening by combination of ultrasound and ion exchange, Ultrasonic Sonochem. 16 (2009) 356-360.

[7] J. Ji, X. Lu, Z. Xu, Effect of ultrasound on adsorption of Geniposide on polymeric resin, Ultrasonics Sonochemistry 13 (2006) 463-470.

[8] J. Ji, X. Lu, M. Cai, Z. Xu, Improvement of leaching process of Geniposide with ultrasound, Ultrasonics Sonochemistry 13 (2006) 455-462. 
Çakıcıoğlu-Özkan F, Erten-Kaya Y. JOTCSA. 2018; 5(sp. is. 1); 53-64.

[9] H. Faghihian, M.K. Amini, A.R. Nezamzadeh, Cerium uptake by zeolite A synthesized from natural clinoptilolite tuffs, Journal of Radio Analytical and Nuclear Chemistry 264 (2005) 577-582.

[10] S.A. Peter, A.S, Moharir, V.R. Jasra, Selective adsorption of oxygen over argon in alkaline-earth-metal cation-exchanged zeolite X, Ind. Eng. Chem. Res. 49 (2010) 7524-7529.

[11] R.V. Jasra, B. Tyagi, Y.M. Badheka, V.N. Choudary, T.S.G. Bhat, Effect of clay binder on sorption and catalytic properties of zeolite pellets, Ind. Eng. Chem. Res. 42 (2003) 3263-3272.

[12] J.-Ch. Buhl, M. Gerstmann, W. Lutz, A. Ritzmann, Hydrothermal stability of the novel zeolite type LSX in comparison to the traditional 13X modification, Hannover, Institut für Mineralogie, 2003. 